\title{
INFLUÊNCIA DA ADIÇÃO DE LIGNINA KRAFT NAS PROPRIEDADES DE PELLETS DE EUCALIPTO
}

\author{
Bárbara Luísa Corradi Pereira ${ }^{1 *}$, Angélica de Cássia Oliveira Carneiro², Ana Márcia Macedo Ladeira Carvalho \\ Benedito Rocha Vital ${ }^{2}$, Aylson Costa Oliveira ${ }^{1}$, Wagner Davel Canal ${ }^{3}$ \\ ${ }^{1 *}$ Universidade Federal de Mato Grosso, Departamento de Engenharia Florestal, Cuiabá, Mato Grosso, Brasil - babicorradi@ gmail.com; \\ aylsoncosta@gmail.com \\ ${ }^{2}$ Universidade Federal de Viçosa, Departamento de Engenharia Florestal, Viçosa, Minas Gerais, Brasil - cassiacarneiro1@gmail.com; \\ ana.marcia@ufv.br; bvital@gmail.com \\ ${ }^{3}$ Universidade Federal de Viçosa, Programa de Pós Graduação em Ciência Florestal, Viçosa, Minas Gerais, Brasil - \\ wagner.d.canal@gmail.com
}

Recebido para publicação: 31/01/2016 - Aceito para publicação: 03/05/2016

\begin{abstract}
Resumo
Os pellets vêm se tornando uma importante fonte renovável de energia para utilização industrial e doméstica. O mercado consumidor está cada vez mais exigente quanto à qualidade do produto e essa pode ser melhorada por meio da utilização de diferentes aditivos, como a lignina kraft. Assim, o objetivo desse trabalho foi avaliar a qualidade dos pellets de eucalipto produzidos com adição de diferentes percentagens de lignina kraft. A matériaprima utilizada para produção de pellets foi madeira com casca de um clone de Eucalyptus grandis x Eucalyptus urophylla com aproximadamente cinco anos de idade, proveniente de plantio comercial, além de $10 \%$ de resíduos da colheita do eucalipto (ponteira, folhas e galhos). Excluindo-se a testemunha ( $0 \%$ de lignina), adicionou-se $1,2,3$, e $5 \%$ de lignina kraft, em relação à massa seca da matéria-prima. Os pellets foram produzidos em uma peletizadora laboratorial com matriz circular horizontal. Foram avaliadas as seguintes propriedades dos pellets: teor de umidade, poder calorífico superior e útil, densidade a granel e aparente, densidade energética, teor de cinzas, comprimento e diâmetro, dureza, durabilidade mecânica e teor de finos. A adição de lignina kraft em pellets de eucalipto contribuiu para a melhoria das propriedades físicas e mecânicas, no que se diz respeito à densidade, durabilidade mecânica, geração de finos e dureza. A adição de lignina ocasionou a elevação dos teores de cinzas e da umidade dos pellets. Conclui-se que a adição de lignina para produção de pellets é viável, desde que sejam utilizadas ligninas com menores teores de cinzas e umidade.

Palavras-chave: Durabilidade mecânica; aditivo; combustível sólido; cinzas.
\end{abstract}

\begin{abstract}
Influence of adding kraft lignin in eucalyptus pellets properties. The pellets are becoming an important renewable source of energy for industrial and domestic use. The consumer market is increasingly demanding in terms of product quality and this may be improved through the use of various additives, such as kraft lignin. The objective of this study was to evaluate the quality of eucalyptus pellets produced with the addition of different percentages of kraft lignin. The raw material used for production of pellets was wood with bark of an Eucalyptus grandis x E. urophylla clone, with approximately five years of age, obtained from commercial planting, and 10\% of waste of eucalyptus harvest (tops, leaves and branches). Excluding the control ( $0 \%$ lignin) was added 1, 2, 3, and $5 \%$ kraft lignin, relative to the dry mass of raw material. The pellets were produced in a laboratory pelletizer with a horizontal circular array. The following properties of the pellets were evaluated: moisture content, gross and net calorific value, unit density, bulk density, energy density, ash content, length and diameter, hardness, mechanical durability and fines content. The addition of kraft lignin contributed to improving the pellets physical and mechanical properties, as regards the density, mechanical durability, fines and hardness. The addition of lignin caused the elevation of the levels of ash and moisture content of the pellets. It is concluded that addition of lignin to pellet production is feasible, since lignin is used with lower contents of ash and moisture.

Keywords: Mechanical durability; additive; solid fuel ash.
\end{abstract}

\section{INTRODUÇÃO}

Nas últimas décadas, os pellets vêm se tornando uma importante fonte renovável de energia para utilização industrial e doméstica. Além disso, observa-se que as exigências relacionadas à qualidade dos pellets para a geração de energia são maiores, o que tornam importantes os estudos relacionados à otimização do processo de produção e homogeneização da matéria-prima. A qualidade dos pellets é determinada por alguns

FLORESTA, Curitiba, PR, v. 46, n. 2, p. 235 - 242, abr. / jun. 2016.

Pereira, B. L. C. et al.

ISSN eletrônico 1982-4688

DOI: $10.5380 /$ rf.v46i2.44936 
índices de qualidade, como a umidade, poder calorífico, densidade a granel, teor de cinzas, durabilidade mecânica e teor de finos (DIN, 2011).

Em relação à matéria-prima, a constituição química, granulometria e umidade são os principais fatores que afetam a qualidades dos pellets (CARROLL; FINNAN, 2012; ZAFARI; KIANMEHR, 2012). Sabe-se que a madeira é a matéria-prima mais utilizada para a produção de pellets devida, principalmente, à baixa geração de cinzas e menor corrosão em equipamentos de combustão quando comparadas a biomassas agrícolas (STELTE et al., 2012). Os pellets de madeira são produzidos, geralmente, a partir de resíduos da indústria madeireira, como serragem, maravalhas, aparas, cavacos e resíduos de colheita (OBERNBERGER; THEK, 2010).

O processo de produção de pellets compreende a secagem e moagem da matéria-prima, sua peletização, seguida de resfriamento e peneiramento. Durante a peletização, a matéria-prima é pressionada por roletes, através de canais de compressão cilíndricos e é convertida em um material aglomerado devido ao amolecimento térmico da lignina que promove a aglutinação das partículas (STELTE et al., 2012). Em relação ao processo, pode-se citar como variáveis que interferem na qualidade dos pellets, a utilização ou não de vaporização e préaquecimento das partículas e os fatores relacionados à peletizadora, como pressão, velocidade dos roletes, dimensões dos canais de compressão, distância entre os roletes e a matriz de compressão (LEE et al., 2013; TUMULURU, 2014). Vale ressaltar que o atrito entre a matéria-prima, os roletes e a matriz irão determinar a temperatura a ser alcançada durante a peletização.

Pode-se, também, melhorar a qualidade dos pellets por meio da utilização de aditivos com propriedades adesivas à matéria-prima (BERGHEL et al., 2013; TARASOV et al., 2013). Os principais aditivos em pellets são amido, farinha de milho ou batata, além de alguns óleos vegetais (OBERNBERGER; THEK, 2010). Segundo Tarasov et al. (2013), as propriedades físicas, mecânicas e energéticas dos pellets podem ser influenciadas pelos aditivos.

A utilização de lignina kraft como aditivo à matéria-prima para produção de pellets é promissora. Isso porque a lignina é uma macromolécula que faz parte da constituição química da madeira e atua na adesão das partículas para a formação dos pellets. Contudo, há poucos trabalhos relacionados ao tema (STEVENS; GARDNER, 2010; BERGHEL et al., 2013). A lignina kraft é obtida do licor negro de fábricas de polpa celulósica pelo processo Kraft, visto que a separação e purificação podem ser feitas por diversos processos industriais. As propriedades da lignina kraft são especificas do processo de extração e irão afetar positiva ou negativamente as propriedades dos pellets (BERGHEL et al., 2013).

No Brasil destacam-se os plantios de eucalipto, cuja madeira e resíduos da colheita e da transformação primária são potenciais matérias-primas para produção de pellets. Contudo, são escassos os trabalhos que avaliam a qualidade de pellets de eucalipto para a geração de energia, como por exemplo, o estudo desenvolvido por Pirraglia et al. (2012) e não há trabalhos sobre pellets de eucalipto provenientes de plantios brasileiros. Além disso, no Brasil, destaca-se a produção de polpa celulósica pelo processo Kraft, onde fábricas otimizadas produzem excedente de energia que é obtida por meio da queima do licor negro. Para aproveitamento do licor negro, além de geração de energia elétrica e vapor, uma das alternativas a serem adotadas é a extração da lignina kraft e sua utilização como aditivo para pellets, dentre outros usos, aplicando-se, portanto, o conceito de biorrefinaria na indústria florestal.

Desse modo, o objetivo desse trabalho foi avaliar a qualidade dos pellets de eucalipto produzidos com adição de diferentes percentagens de lignina kraft.

\section{MATERIAL E MÉTODOS}

\section{Material}

A matéria-prima utilizada para produção de pellets (Tabela 1) foi madeira com casca de um clone de Eucalyptus grandis x Eucalyptus urophylla, com aproximadamente cinco anos de idade, proveniente de plantio comercial de uma empresa florestal, localizado em Nova Era, Minas Gerais. A percentagem de casca era de aproximadamente $10 \%$ e o incremento médio anual (com casca) igual a $54,95 \mathrm{~m}^{3}$. ha $\mathrm{ha}^{-1}$. ano ${ }^{-1}$.

Foram selecionadas três árvores de diâmetro médio, cuja madeira com casca foi transformada em cavacos. Posteriormente, os cavacos foram processados em moinho martelo e classificados em peneira com malha de dois milímetros. Adicionou-se $10 \%$ de resíduos da colheita do eucalipto (ponteira, folhas e galhos), em relação à massa seca de madeira com casca, previamente triturados em moinho martelo e classificados em peneira com malha de dois milímetros. Após a homogeneização do material, efetuou-se secagem em estufa com circulação de ar, a $75^{\circ} \mathrm{C}$. Na tabela 1 encontra-se a caracterização da matéria-prima utilizada para produção dos pellets.

A lignina kraft (Tabela 1) foi utilizada como aditivo para a produção de pellets. Excluindo-se a testemunha (0\% de lignina), adicionou-se $1,2,3$, e 5\% de lignina kraft, em relação à massa seca da matériaprima. A lignina kraft, foi extraída do licor negro pelo processo LignoBoost e é uma amostra adquirida de uma indústria de celulose e papel situada no Brasil. Este processo, de acordo com Berghel et al. (2013), baseia-se na precipitação da lignina pela redução gradual do pH do licor negro, seguida de filtração, lavagem e desidratação. 
Tabela 1. Propriedades da matéria-prima proveniente de eucalipto e da lignina Kraft.

Table 1. Properties of the raw material from eucalyptus and kraft lignin.

\begin{tabular}{lccc}
\hline Propriedade & Unidade & Eucalipto & Lignina kraft \\
\hline Umidade (base úmida) & $\%$ & 11,79 & 14,53 \\
Poder calorífico superior & $\mathrm{MJ.} \mathrm{kg}$ & 19,58 & 21,67 \\
Densidade a granel & $\mathrm{kg} \cdot \mathrm{m}^{-3}$ & 181,7 & 616,5 \\
Cinzas & $\%$ & 1,50 & 16,32 \\
Lignina total & $\%$ & 30,80 & 76,40 \\
Extrativos totais & $\%$ & 8,31 & ND \\
\hline
\end{tabular}

ND: Não determinado.

\section{Produção dos Pellets}

Os pellets foram produzidos em uma prensa peletizadora laboratorial com matriz circular horizontal da marca Amandus Kahl, modelo 14-175 com capacidade para produção de $50 \mathrm{~kg} \cdot \mathrm{h}^{-1}$. As dimensões dos canais de compressão da matriz consistiam em diâmetro interno de $6,0 \mathrm{~mm}$ e o comprimento de $20,0 \mathrm{~mm}$.

Produziram-se aproximadamente $1,5 \mathrm{~kg}$ de pellets por lote, sendo três lotes por biomassa tratamento (proporção de lignina kraft adicionada). Para alimentação da peletizadora, utilizou-se um sistema composto por um motor elétrico, um controlador de velocidade e uma rosca sem fim. A temperatura de peletização variou de 95 a $100{ }^{\circ} \mathrm{C}$ e a velocidade de rotação dos roletes foram de $1500 \mathrm{rpm}$.

\section{Propriedades dos Pellets}

$\mathrm{O}$ teor de umidade em base úmida dos pellets, depois de acondicionados por sete dias, foi determinada de acordo com a metodologia descrita na norma DIN EN 14774-1 (DIN, 2010a), em estufa a $105 \pm 2{ }^{\circ} \mathrm{C}$.

Para determinação do PCS e percentagem de cinzas, as amostras foram transformadas em serragem, utilizando-se um moinho de laboratório tipo Wiley. Para PCS e percentagem de cinzas, foi utilizada a fração serragem que passou pela peneira com malha de 40 mesh e ficou retida na peneira com malha de 60 mesh.

O Poder Calorífico Superior (PCS) foi obtido de acordo com a norma da DIN EN 14918 (DIN, 2010b). Para tal, utilizou-se uma bomba calorimétrica adiabática marca IKA® modelo 300. A estimativa do Poder Calorífico Útil (PCU) foi realizada conforme o Anexo E da norma DIN EN 14918 (DIN, 2010b).

A porcentagem de cinzas foi determinada de acordo com a norma DIN EN 14775 (DIN, 2009).

A determinação da densidade aparente de um pellet foi obtida pelo método pelo método hidrostático, por meio da imersão em mercúrio.

A determinação da densidade a granel dos pellets foi determinada de acordo com a norma DIN EN 15103 (DIN, 2010c).

A densidade energética, em GJ. $\mathrm{m}^{-3}$, foi obtida pela multiplicação do poder calorífico útil pela densidade a granel do material, conforme sugerido por Obernberger e Thek (2010).

A durabilidade mecânica e a porcentagem de finos (partículas menores que 3,15 mm) foram determinadas utilizando-se o equipamento Ligno-Tester, Holmen ${ }^{\circledR}$, de acordo com a norma DIN EN 15210-1 (DIN, 2010d) e instruções do equipamento. As amostras de pellets são ventiladas por meio de um jato de ar que simula a destruição natural dos pellets durante o transporte e manuseio, em uma câmara com formato de pirâmide quadrangular invertida. Para a determinação da porcentagem de finos, o fluxo de ar tinha pressão de 30 mbar e duração de 30 segundos e utilizou-se uma amostra de $0,300 \mathrm{~kg}$ de pellets. Posteriormente, as amostras sem finos foram submetidas a outro fluxo de ar controlado (70 mbar) durante 60 segundos para determinação da durabilidade mecânica, utilizando-se $0,100 \mathrm{~kg}$ de pellets.

A dureza, em kgf, foi determinada pelo ensaio de compressão diametral do pellet em um durômetro manual com escala de 0 a 100 kgf, da marca Amandus Kahl. Um pellet, por vez, foi inserido no durômetro e foi aplicada carga crescente, até fratura da amostra. Então, fez-se a leitura da carga máxima, em kgf, que um pellet pode suportar antes de rachar. Foi avaliada a dureza de trinta pellets por lote.

O diâmetro $(\mathrm{mm})$ e comprimento $(\mathrm{mm})$ dos pellets foram obtidos conforme a norma DIN EN 16127 (DIN, 2012), com medição realizada em paquímetro digital.

\section{Classificação dos Pellets de acordo com Normas de Qualidade}

Os pellets de eucalipto foram classificados como pellets de madeira, cujas especificações de qualidade estão na norma DIN EN 14961-2 (DIN, 2011) (Tabela 2). Esta norma refere-se à da qualidade de pellets de madeira para uso não industrial. A classe A2 foi utilizada para fins de comparação da qualidade dos pellets produzidos neste trabalho, devido às matérias-primas serem madeira, além de casca e resíduos da colheita. 
Tabela 2. Especificações para pellets de madeira.

Table 2. Specifications for wood pellets.

\begin{tabular}{lcc}
\hline Propriedade & Unidade & Classe: A2* \\
\hline Diâmetro & $\mathrm{mm}$ & $6 \pm 1$ \\
Comprimento & $\mathrm{mm}$ & $3,15 \leq$ Comprimento $\leq 40$ \\
Umidade base úmida & $\%$ & $\leq 10$ \\
Teor de cinzas & $\%$ & $\leq 1,5$ \\
Durabilidade mecânica & $\%$ & $\geq 97,5$ \\
Finos & $\%$ & $\leq 1,0$ \\
Poder Calorífico Útil - PCU & $\mathrm{MJ.} \mathrm{kg}$ & $16,3 \leq \mathrm{PCU} \leq 19$ \\
Densidade a granel & $\mathrm{kg} \cdot \mathrm{m}^{-3}$ & $\geq 600$ \\
\hline
\end{tabular}

*Origem da matéria-prima: Árvores inteiras sem raízes, madeira de tronco, resíduos de colheita, casca, madeira sem tratamento químico. Fonte: Adaptado de DIN EN 14961-2 (DIN, 2011).

\section{Análise Estatística}

$\mathrm{O}$ experimento foi instalado segundo um delineamento inteiramente casualizado, com cinco tratamentos (Tabela 3) e três repetições (lotes de pellets), totalizando 15 unidades amostrais.

Tabela 3. Percentagens de biomassa de eucalipto e lignina kraft utilizadas.

Table 3. Eucalyptus biomass percentages and kraft lignin used.

\begin{tabular}{lcc} 
Tratamento & Eucalipto $(\%)$ & Lignina $\boldsymbol{k r a f t}(\%)$ \\
\hline I & 100 & 0 \\
II & 99 & 1 \\
III & 98 & 2 \\
IV & 97 & 3 \\
V & 95 & 5 \\
\hline
\end{tabular}

Os dados foram submetidos aos testes de Lilliefors, para testar a normalidade, e Cochran, para testar a homogeneidade das variâncias. Em seguida os resultados foram submetidos à análise de variância (ANOVA), para verificação das diferenças existentes entre os tratamentos. Quando estabelecidas diferenças significativas entre eles, aplicou-se o teste Tukey em nível de 95\% de significância.

\section{RESULTADOS}

Observou-se que o teor de umidade dos pellets (Tabela 4) foi menor do que da matéria-prima (Tabela 1) e quanto maior a percentagem de lignina kraft adicionada, maior foi o teor de umidade dos pellets, devido, provavelmente, ao maior teor de umidade da lignina em relação à matéria-prima. As partículas de eucalipto tinham o teor médio de umidade $_{\mathrm{bu}}$ de $11,79 \%$ e a lignina kraft, 14,53\%. mA variação do teor de umidade dos pellets, considerando-se os produzidos com 0 e $5 \%$ de lignina kraft foi, em média, igual a 16,7\% (Tabela 4).

Tabela 4. Valores médios de umidade, poder calorífico útil e teor de cinzas dos pellets em função do teor de lignina Kraft.

Table 4. Mean values of moisture, net calorific value and ashes in function of kraft lignin contentes.

\begin{tabular}{lccc}
\hline Lignina kraft (\%) & Umidade $_{\mathbf{b u}}(\%)$ & PCU $\left(\mathbf{M J} \mathbf{~ k g}^{-1}\right)$ & Cinzas $(\%)^{(\%)}$ \\
\hline 0 & $7,05 \mathrm{~d}^{(0,03)}$ & $16,92 \mathrm{a}^{(0,01)}$ & $1,41 \mathrm{e}^{(0,01)}$ \\
1 & $7,66 \mathrm{c}^{(0,13)}$ & $16,91 \mathrm{ab}^{(0,03)}$ & $1,55^{*} \mathrm{~d}^{(0,02)}$ \\
2 & $7,97 \mathrm{~b}^{(0,08)}$ & $16,86 \mathrm{bc}^{(0,02)}$ & $1,67^{*} \mathrm{c}^{(0,03)}$ \\
3 & $8,07 \mathrm{~b}^{(0,05)}$ & $16,80 \mathrm{c}^{(0,01)}$ & $1,76^{*} \mathrm{~b}^{(0,04)}$ \\
5 & $8,42 \mathrm{a}^{(0,07)}$ & $16,65 \mathrm{~d}^{(0,01)}$ & $1,98^{*} \mathrm{a}^{(0,01)}$ \\
\hline
\end{tabular}

Umidade $_{\mathrm{bu}}=$ Umidade, em base úmida. * Valores superiores ao permitido pela norma DIN EN 14961-2 (DIN, 2011). Médias, na coluna, seguidas da mesma letra não diferem entre si, em $5 \%$ de probabilidade de erro, pelo teste Tukey. ${ }^{(\ldots)}$ Desvio Padrão.

O Poder Calorífico Superior (PCS) dos pellets foi semelhante para todos os tratamentos, 19,76 ${\mathrm{MJ} . \mathrm{kg}^{-1} \pm}^{-1}$ 0,09, não havendo efeito da adição de lignina kraft no PCS dos pellets (Tabela 4).

Apesar da diferença significativa entre os valores de PCU, numericamente esta diferença não é acentuada. Observa-se uma diminuição de 1,6\% no PCU, quando se compara os pellets com adição de 5\% de lignina com o tratamento sem adição (Tabela 4). Os pellets de todos os tratamentos apresentaram valores médios

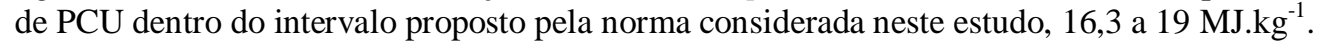


Quanto maior a percentagem de lignina kraft adicionada à matéria-prima, maior o teor de cinzas dos pellets (Tabela 4). Apenas o teor de cinzas dos pellets com 0 e $1 \%$ de lignina kraft atenderam à especificação da norma cujo teor máximo de cinza permitido é $1,5 \%$, para a classe A2.

A adição de lignina kraft promoveu o aumento da densidade aparente, densidade a granel e densidade energética dos pellets (Tabela 5).

Tabela 5. Valores médios de densidade aparente, densidade a granel e densidade energética dos pellets em função do teor de lignina kraft.

Table 5. Mean values of unit density, bulk density and energy density in function of kraft lignin contents.

\begin{tabular}{|c|c|c|c|}
\hline Lignina $k r a f t(\%)$ & $\begin{array}{c}\text { Densidade aparente } \\
\left(\mathrm{kg} . \mathrm{m}^{-3}\right)\end{array}$ & $\begin{array}{c}\text { Densidade a granel } \\
\left(\mathrm{kg} . \mathrm{m}^{-3}\right)\end{array}$ & $\begin{array}{c}\text { Densidade Energética } \\
\left(\mathbf{G J} \cdot \mathrm{m}^{-3}\right)\end{array}$ \\
\hline 0 & $1096,2 \mathrm{~b}^{(15,35)}$ & $601,5 \mathrm{e}^{(0,16)}$ & $10,18 \mathrm{~d}^{(0,01)}$ \\
\hline 1 & $1117,9 a b^{(14,15)}$ & $605,3 \mathrm{~d}^{(1,17)}$ & $10,23 \mathrm{c}^{(0,03)}$ \\
\hline 2 & $1118,3 \mathrm{ab}^{(10,91)}$ & $610,5 \mathrm{c}^{(0,57)}$ & $10,29 \mathrm{~b}^{(0,02)}$ \\
\hline 3 & $1137,3 \mathrm{ab}^{(17,85)}$ & $627,3 \mathrm{~b}^{(0,32)}$ & $10,52 \mathrm{a}^{(0,01)}$ \\
\hline 5 & $1163,4 \mathrm{a}^{(16,50)}$ & $631,5 \mathrm{a}^{(0,21)}$ & $10,54 \mathrm{a}^{(0,01)}$ \\
\hline
\end{tabular}

Devido à relação entre as densidades aparente e a granel (TARASOV et al., 2013), esta última também foi influenciada positivamente pela adição de lignina kraft (Tabela 5).

A densidade energética (Tabela 5) depende do PCU e da densidade a granel dos pellets. O PCU diminuiu $1,6 \%$, porém a densidade a granel aumentou cerca de 5,0\%, considerando-se a adição de 0 e $5 \%$ de lignina kraft. Tal fato ocasionou o aumento significativo da densidade energética dos pellets até a adição de $3 \%$ de lignina kraft.

Na tabela 6 são apresentados os valores médios de durabilidade mecânica, finos e dureza dos pellets com adição de lignina kraft.

Tabela 6. Valores médios de durabilidade mecânica, percentagem de finos e dureza em função do teor de lignina kraft presente em pellets de eucalipto.

Table 6. Mean values of mechanical durability, fines and hardness in function of kraft lignin contents.

\begin{tabular}{lccc}
\hline Lignina kraft (\%) & Durabilidade mecânica (\%) & Percentagem de finos (\%) & Dureza (kgf) \\
\hline 0 & $93,98^{*} \mathrm{~d}$ & $0,53 \mathrm{a}$ & $33,67 \mathrm{~d}$ \\
1 & $97,21^{*} \mathrm{c}$ & $0,15 \mathrm{~b}$ & $37,33 \mathrm{~cd}$ \\
2 & $98,52 \mathrm{~b}$ & $0,12 \mathrm{bc}$ & $41,00 \mathrm{bc}$ \\
3 & $99,00 \mathrm{ab}$ & $0,12 \mathrm{bc}$ & $43,67 \mathrm{~b}$ \\
5 & $99,18 \mathrm{a}$ & $0,10 \mathrm{c}$ & $54,33 \mathrm{a}$ \\
\hline
\end{tabular}

*Valores em não conformidade com a norma DIN EN 14961-2 (DIN, 2011). Médias, na coluna, seguidas da mesma letra não diferem entre si, em 5\% de probabilidade de erro, pelo teste Tukey. ${ }^{(.)}$Desvio Padrão.

Os resultados demonstraram que a adição de $1 \%$ de lignina foi suficiente para acrescer o valor médio de durabilidade mecânica dos pellets em 3,4\%. Já a adição de 5\% de lignina promoveu aumento dessa propriedade em $5,5 \%$ (Tabela 6).

De acordo com a norma de classificação de pellets DIN EN 14961-2 (DIN, 2011), a durabilidade mecânica dos pellets, que simula a resistência dos pellets à impactos mecânicos durante o armazenamento e transporte, deve ser maior ou igual a 97,5\%. Os pellets produzidos sem adição de lignina kraft não apresentaram conformidade com a norma, com valor médio de $94 \%$ para a referida propriedade, em quanto que a adição de $1 \%$ de lignina foi suficiente para acrescer o valor médio de durabilidade mecânica dos pellets em 3,4\%. Já a adição de 5\% de lignina promoveu aumento dessa propriedade em 5,5\% (Tabela 6), estando em conformidade com a norma. A percentagem de finos, independente do tratamento, ficou abaixo do máximo permitido pela norma alemã que estipula valores inferiores a $1 \%$ (Tabela 6). Contudo, observou-se que a adição de lignina kraft proporcionou a diminuição da percentagem de finos gerada.

Em relação à dureza (Tabela 6), observa-se um aumento dessa característica com o acréscimo da percentagem de lignina kraft adicionada. A adição de lignina Kraft não teve nenhum efeito nas dimensões dos pellets. Os valores médios, seguidos pelos desvios padrões, de diâmetro e comprimento dos pellets foram $6,11 \pm 0,06$ e $20,14 \pm 0,86$, respectivamente.

FLORESTA, Curitiba, PR, v. 46, n. 2, p. 235 - 242, abr. / jun. 2016

Pereira, B. L. C. et al.

ISSN eletrônico 1982-4688

DOI: $10.5380 /$ rf.v46i2.44936 


\section{DISCUSSÃO}

A umidade da matéria-prima é maior que a umidade dos pellets (Tabela 4) porque parte da água contida no material é liberada, na forma de vapor de água, devido à alta temperatura alcançada durante a peletização, entre 95 e $100{ }^{\circ} \mathrm{C}$, resultante do atrito entre a matéria-prima, os rolos e a matriz. Berghel et al. (2013) ao avaliarem a qualidade de pellets madeira de abeto (Picea abies) com adição de lignina kraft seca (teor de umidade $_{\mathrm{bu}}$ menor que $10 \%$ ) e lignina kraft úmida (teor de umidade $\mathrm{bu}_{\mathrm{b}}$ entre 30 e $40 \%$ ) observaram que os pellets com maior teor de umidade eram aqueles com adição de lignina úmida. No presente estudo, o aumento da umidade com o aumento do teor de lignina indica, provavelmente, a contaminação deste aditivo com carboidratos, que são hidrofílicos. Vale ressaltar que todos os tratamentos tiveram umidade inferior a 10\%, teor máximo estabelecido pela norma DIN EN 14961-2 (DIN, 2011).

Segundo Demirbas (2002), maiores teores de lignina contribuem com aumento do poder calorífico superior do combustível porque o PCS da lignina é maior que dos outros componentes primários da madeira. Stevens e Gardner (2010) verificaram que a adição de lignina em pó aumentava o poder calorífico dos pellets. Berghel et al. (2013) ao utilizarem lignina kraft com baixo teor de cinzas (0,2 a 1,4\%) como aditivo em pellets

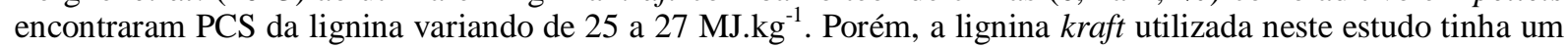
alto teor de cinzas $(16,32 \%)$, o qual se relaciona negativamente com o PCS. Foi observado valor de PCS da lignina kraft próximo ao da matéria-prima proveniente do eucalipto, 19,58 e 21,67 MJ.kg-1, respectivamente. Portanto, o PCS da lignina não foi suficientemente elevado para contribuir para o aumento do PCS dos pellets, visto que a percentagem máxima de lignina adicionada foi $5 \%$.

$\mathrm{O}$ crescente aumento do teor de cinzas com a adição de lignina deve-se à alta concentração de inorgânicos presentes na lignina kraft utilizada neste estudo, 16,32\%, visto que a matéria-prima tinha um teor de cinzas igual a $1,50 \%$ e não havia nenhuma fonte de contaminação durante a preparação da matéria-prima a ser peletizada. A adição de lignina pode aumentar ou diminuir a qualidade dos pellets (BERGHEL et al., 2013), o que depende, principalmente, do método utilizado para extraí-la e purificá-la. Teores de cinza elevados são indesejáveis para pellets por inúmeros fatores, dentre eles, a relação inversamente proporcional ao PCS, além de ser o resíduo da combustão e dependendo da constituição química das cinzas, pode-se formar incrustações nos equipamentos de combustão (OBERNBERGER; THEK, 2010).

$\mathrm{O}$ aumento nos valores médios de densidade associado a maiores teores de lignina Kraft é devido à densidade a granel ser determinada pela massa de pellets contida em um recipiente com volume fixo. Portanto, quanto maior for a densidade aparente dos pellets, menor o volume que uma massa de pellets irá ocupar.

Durante a peletização, as partículas rearranjam-se de modo a preencher o canal de compressão e o ar localizado entre elas é removido. Adicionalmente, nas partículas que estão próximas, há ligações fracas por meio de forças de van der Waals e forças eletrostáticas, que promovem sua união (STELTE et al., 2012). Devido às altas temperaturas alcançadas durante a peletização, em torno de $100{ }^{\circ} \mathrm{C}$, a lignina é plasticizada e funciona como agente de ligação entre as partículas (KALIYAN; MOREY, 2010; CARROLL; FINNAN, 2012). Segundo Narra et al. (2010), a lignina forma uma fina camada sobre as partículas, o que contribui para melhorar a ligação entre elas. Isto porque há interdifusão molecular e entrelaçamento entre cadeias adjacentes, fenômeno descrito como "ponte sólida" por Kaliyan e Morey (2010), ou seja, há formação de uma rede de macromoléculas que se fundem e posteriormente, solidificam-se (Stelte et al., 2012).

Portanto, quanto maior a percentagem de lignina kraft adicionada, mais efetivas foram as ligações entre as partículas, melhorando a densificação do material o que acarretou em maior densidade aparente dos pellets (Tabela 5). Contudo, a densidade aparente dos pellets somente pode atingir um valor máximo que corresponde à densidade da parede celular (Stelte et al., $2011 \mathrm{a}$ ), cerca de $1500 \mathrm{~kg} . \mathrm{m}^{-3}$. Apesar de não ser normatizada, Tarasov et al. (2013) recomendaram densidade aparente dos pellets entre 1000 e $1400 \mathrm{~kg} . \mathrm{m}^{-3}$. Verificou-se que as densidades dos pellets avaliados estão dentro do limite sugerido.

De acordo com a norma de classificação, a densidade a granel dos pellets deve ser maior que $600 \mathrm{~kg} . \mathrm{m}^{-3}$. Os valores médios de densidade a granel de todos os tratamentos, com ou sem adição de lignina kraft, se enquadraram à especificação. Considerando-se o ponto de vista econômico, o aumento da densidade a granel reduz significativamente os custos de armazenamento e transporte, e também aumenta a densidade energética (Narra $e t$ al., 2010). Neste aspecto, maiores teores de lignina kraft deveriam ser adicionados à matéria-prima para produção de pellets.

Pellets com maior densidade energética são desejáveis porque liberam, durante a sua queima, maior quantidade de energia por unidade volumétrica, ou seja, a quantidade de energia transportada ou armazenada em um mesmo volume é aumentada quando tem-se pellets com maiores densidades energéticas. Contudo, a densidade energética teve um incremento energético baixo, igual a $0,35 \mathrm{GJ}^{-3} \mathrm{~m}^{-3}$, o que corresponde a um aumento de $3,4 \%$ da densidade energética dos pellets com adição de 5\% de lignina kraft quando comparados aos pellets sem adição de lignina.

A resistência mecânica dos pellets aumentou com a adição de lignina kraft devido à elevação da durabilidade mecânica e a dureza e ao decréscimo da percentagem de geração de finos (Tabela 6). A alta 
durabilidade mecânica é necessária para que os pellets mantenham sua forma durante o transporte e armazenamento. Isto porque quanto maior a durabilidade mecânica, menor é presença de finos, sendo que grandes quantidades de finos podem causar problemas durante a estocagem e o processo de combustão, além de perigos relacionados com a saúde de operários e riscos de explosão (FILBAKK et al., 2011).

Salienta-se que os mecanismos de ligação entre as partículas em pellets de madeira, são devido, principalmente à lignina, componente químico da madeira que atua como um agente de ligação entre as partículas durante a peletização (KALIYAN; MOREY, 2009). Com o aumento da temperatura, a energia das moléculas de lignina aumenta, ligações intermoleculares são enfraquecidas e ocorrem rotações em torno das ligações covalentes, o que torna a lignina flexível, passando do estado vítreo para plástico (KALIYAN; MOREY, 2010; STELTE et al., 2011b). A temperatura em que este fenômeno ocorre denomina-se temperatura de transição vítrea e depende da composição da lignina e da presença de um agente plasticizante, como a água, e varia de 50 a $100{ }^{\circ} \mathrm{C}$ (STELTE et al., 2011b). A umidade da matéria-prima, as temperaturas elevadas e a pressão no processo de compactação contribuem para o aumento a fluidez da lignina, elevando a área de contato e a possibilidade de interpenetração de moléculas de lignina entre duas partículas (STELTE et al., 2012). Portanto, pressionando-se a madeira acima da temperatura de transição vítrea, as propriedades mecânicas dos pellets são melhoradas. Assim como a lignina presente na madeira (in natura), a lignina kraft também contribuiu para melhorar a aglutinação das partículas que compõe os pellets.

Observou-se que a adição de $2 \%$ de lignina kraft foi suficiente para aumentar a durabilidade mecânica dos pellets e atender às especificações da norma. Portanto, quando objetiva-se diminuir problemas relacionados à desintegração de pellets, a adição de lignina kraft mostrou-se apropriada (BERGHEL et al., 2013). Estes autores também encontraram relação entre a adição de lignina kraft e o aumento da durabilidade mecânica dos pellets.

A diminuição da percentagem de finos indica que a adição de lignina kraft proporcionou maior resistência e maior ligação entre as partículas, favorecendo dessa forma as atividades de manuseio, transporte e armazenamento.

De acordo com Zamorano et al. (2011) a resistência à compressão dos pellets está relacionada com as forças de adesão entre as partículas. Então, provavelmente, quanto maior a quantidade de lignina kraft, mais pontos de contato entre as partículas que compõe os pellets, maior a adesão e portanto, maior a dureza.

O comprimento e o diâmetro dos pellets não foram influenciados pela adição de lignina kraft porque tais dimensões são pré-determinadas. O diâmetro dos pellets é determinado pelo diâmetro dos canais de compressão da matriz peletizadora e o comprimento, por facas que se situam abaixo da matriz, de modo que o comprimento não ultrapassa um máximo definido pela altura das facas. De acordo com Narra et al. (2010) as dimensões e forma dos pellets devem ser homogêneas para o melhor funcionamento de fornalhas de pequena escala e equipamentos automáticos de aquecimento. $\mathrm{O}$ diâmetro e o comprimento dos pellets estão de acordo com as exigências da norma.

\section{CONCLUSÕES}

Os resultados obtidos permitem concluir que:

- A adição de lignina kraft em pellets de eucalipto contribui para melhorar as propriedades físicas e mecânicas, no que se diz respeito à densidade, durabilidade mecânica, geração de finos e dureza.

- A classificação de acordo com os padrões da norma adotada neste estudo não foi satisfatória, porque a adição de $1 \%$ de lignina não foi suficiente para elevar a durabilidade mecânica ao mínimo exigido e a adição de $2 \%$ ou mais elevaram o teor de cinzas acima do máximo permitido.

- A adição de lignina kraft para produção de pellets é viável, desde que sejam utilizadas ligninas mais puras, com menores teores de cinzas e umidade.

\section{AGRADECIMENTOS} respectivamente.

\section{REFERÊNCIAS}

BERGHEL, J.; FRODESON, S.; GRANSTROM, K.; RENSTROM, R.; STAHL, M.; NORDGREN, D.; TOMANI, P. The effects of kraft lignin additives on wood fuel pellet quality, energy use and shelf life. Fuel Processing Technology, v. 112, p. 64 - 69, 2013.

CARROLL, J. P.; FINNAN, J. Physical and chemical properties of pellets from energy crops and cereal straws. Biosystems Engineering, v. 112, n. 2, p. 151 - 159, 2012. 
DEMIRBAS, A. Relationships between heating value and lignin, moisture, ash and extractive contents of biomass fuels. Energy, Exploration \& Exploitation, v. 20, n. 1, p. 105 - 111, 2002.

DEUTSCHES INSTITUT FÜR NORMUNG. DIN EN 14775: Determination of ash content. Berlim: CEN, 2009. 12 p.

DIN EN 14774-1: Determination of moisture content - Oven dry method - Part 1: Total moisture

- Reference method. Berlim: CEN, 2010a. 10 p.

DIN EN 14918: Determination of calorific value. Belim: CEN, 2010b. 63 p.

DIN EN 15103: Determination of bulk density. Berlim: CEN, 2010c. 14 p.

DIN EN 15210-1: Solid biofuels - Determination of mechanical durability of pellets and briquettes

- Part 1: Pellets. Berlim: CEN, 2010d. 12 p.

DIN EN 14961-2: Solid biofuels - Fuel specifications and classes - Part 2: Wood pellets for nonindustrial use. Berlim: CEN, 2011. 15 p.

DIN EN 16127: Determination of length and diameter of pellets. Berlim: CEN, 2012. 11 p.

FILBAKK, T.; JIRJIS, R.; NURMI, J.; HOIBO, O. The effect of bark content on quality parameters of Scots pine (Pinus sylvestris L.) pellets. Biomass \& Bioenergy, v. 35, n. 8, p. 3342 - 3349, 2011.

KALIYAN, N.; MOREY, R. V. Factors affecting strength and durability of densified biomass products. Biomass \& Bioenergy, v. 33, n. 3, p. 337 - 359, 2009.

KALIYAN, N.; MOREY, R. V. Natural binders and solid bridge type binding mechanisms in briquettes and pellets made from corn stover and switchgrass. Bioresource Technology, v. 101, n. 3, p. 1082 - 1090, 2010.

LEE, S. M.; AHN, B. J.; CHOI, D. H.; HAN, G. S.; JEONG, H. S.; AHN, S. H.; YANG, I. Effects of densification variables on the durability of wood pellets fabricated with Larix kaempferi C. and Liriodendron tulipifera L. sawdust. Biomass \& Bioenergy, v. 48, p. 1 - 9, 2013.

NARRA, S.; TAO, Y.; GLASER, C.; GUSOVIUS, H. J.; AY, P. Increasing the Calorific Value of Rye Straw Pellets with Biogenous and Fossil Fuel Additives. Energy \& Fuels, v. 24, p. 5228 - 5234, 2010.

OBERNBERGER, I.; THEK, G. The pellet handbook: The production and thermal utilisation of pellets. London: Earthscan, 2010. 593 p.

PIRRAGLIA, A.; GONZALES, R.; SALONI, D.; WRIGHT, J.; DENIG, J. Fuel properties and suitability of Eucalyptus benthamii and Eucalyptus macarthurii for torrefied wood and pellets. Bioresources, v. 7, n. 1, p. 217 - 235, 2012.

STELTE, W.; HOLM, J. K.; SANADI, A. R.; BARSBERG, S.; AHRENFELDT, J.; HENRIKSEN, U. B. Fuel pellets from biomass: The importance of the pelletizing pressure and its dependency on the processing conditions. Fuel, v. 90, n. 11, p. 3285 - 3290, 2011a.

STELTE, W.; HOLM, J. K.; SANADI, A. R.; BARSBERG, S.; AHRENFELDT, J.; HENRIKSEN, U. B. A study of bonding and failure mechanisms in fuel pellets from different biomass resources. Biomass and Bioenergy, v. 35, n. 2, p. $910-918,2011$ b

STELTE, W.; SANADI, A. R.; SHANG, L.; HOLM, J. K.; AHRENFELDT, J.; HENRIKSEN, U. B. Recent developments in biomass pelletization - a review. Bioresources, v. 7, n. 3, p. 4451 - 4490, 2012.

STEVENS, J.; GARDNER, D. J. Enhancing the Fuel Value of Wood Pellets with the Addition of Lignin. Wood and Fiber Science, v. 42, n. 4, p. 439 - 443, 2010.

TARASOV, D.; SHAHI, C.; LEITCH, M. Effect of Additives on Wood Pellet Physical and Thermal Characteristics: A Review. ISRN Forestry, v. 2013, p. 6, 2013.

TUMULURU, J. S. Effect of process variables on the density and durability of the pellets made from high moisture corn stover. Biosystems Engineering, v. 119, p. 44 - 57, 2014.

ZAFARI, A.; KIANMEHR, M. H. Effect of Raw Material Properties and Die Geometry on the Density of Biomass Pellets from Composted Municipal Solid Waste. Bioresources, v. 7, n. 4, p. 4704 - 4714, 2012.

ZAMORANO, M.; POPOV, V.; RODRÍGUEZ, M. L.; GARCÍA-MARAVER, A. A comparative study of quality properties of pelletized agricultural and forestry lopping residues. Renewable Energy, v. 36, n. 11, p. 3133 - 3140, 2011. 